\title{
Adipose Tissue Transplant Impregnated with Collagen Increases Engraftment by Promoting Cell Proliferation, Neovascularization, and Macrophage Activity in a Rat
}

Chika Suzuki ( $\nabla$ chachanchan0613@gmail.com )

Department of Plastic Surgery, Tokyo Medical University, Tokyo, Japan

Takako Komiya

Department of Plastic Surgery, Tokyo Medical University, Tokyo, Japan

Hana Inoue

Department of Physiology, Tokyo Medical University, Tokyo, Japan

\section{Takayuki Yoshimoto}

Department of Immunoregulation, Institute of Medical Science, Tokyo Medical University, Tokyo, Japan Hajime Matsumura

Department of Plastic Surgery, Tokyo Medical University, Tokyo, Japan

\section{Research Article}

Keywords: effect, proliferation, engraftment, mRNA

Posted Date: January 21st, 2021

DOI: https://doi.org/10.21203/rs.3.rs-143232/v1

License: (c) (i) This work is licensed under a Creative Commons Attribution 4.0 International License.

Read Full License 


\section{Abstract}

Objectives: To clarify the effect of impregnating transplanted adipose tissue with collagen on angiogenesis, cell proliferation, and tissue remodeling process and to reveal whether collagen impregnation contributes to improving the engraftment of transplanted adipose tissue in rats.

Methods: Adipose tissue was harvested from the inguinal and injected into the back of the rat, in addition to collagen. Engraftment tissue was harvested, semi-quantitatively evaluated and underwent HE or Perilipin staining. Moreover, we evaluated viable adipocyte counts and neovascularization. Macrophages were evaluated using flow cytometry, and the adiponectin or VEGF mRNA was detected using real-time PCR.

Results: By impregnating transplanted adipose tissue with collagen, higher engraftment rate semiquantitatively and a greater number of new blood vessels histologically were identified. Perilipin staining revealed a higher adipocyte number. The total cell, M1 macrophage, and M2 macrophage count were higher. There was increased adiponectin mRNA significantly at week 4 compared to that at week 1 after transplantation. Note that the expression levels of VEGF mRNA increased.

Discussion: In rats, collagen impregnation enhanced cell proliferation, induced M2 macrophages, which are involved in wound healing, and promoted adipocytes and neovascularization. Therefore, impregnating transplanted adipose tissue with collagen could increase the engraftment rate of adipose tissue.

\section{Introduction}

Adipose tissue transplantation is a relatively minimal invasive procedure; because it can be performed relatively easily and does not require advanced techniques such as for vascular anastomosis, it is widely performed in various settings such as in reconstruction after craniofacial surgery and following mastectomy [1-6]. However, as per the current method, the amount per transplant is limited; because there is no blood flow in transplanted adipose tissue, the tissue might become ischemic. If this happens, the majority of cases develop necrosis, thus making graft survival unstable and making multiple transplants necessary in multiple cases [2,7-9]. Many studies have indicated that there is considerable discrepancy with regard to the related effects and complications of adipose tissue transplantation, which vary as per the level of skill of the surgeon. Thus, the current method still has room for improvement [8, 10]. Transplanted adipose tissue is engrafted through the penetration of capillaries from surrounding tissue. However, this process requires time and when blood flow cannot be maintained, it becomes fat necrosis and scar tissue [2]. Therefore, to stabilize and achieve engraftment of adipose tissue transplants, the reperfusion of blood flow to the adipose tissue needs to be achieved more quickly. Furthermore, the tolerance to ischemia of the actual transplanted adipose tissue needs to be improved. Previously, we reported that adding lipid fraction obtained from adipose tissue to artificial dermis induces early neovascularization in the artificial dermis [11]. When the artificial dermis contains collagen, this 
collagen induces neovascularization. Therefore, based on this empirical data, it is possible that while the mechanism is unclear, the interaction between collagen and adipocytes strongly enhances neovascularization. The purpose of this study is to clarify the effect of collagen impregnation to transplanted adipose tissue on angiogenesis, cell proliferation, and tissue remodeling process, as well as to reveal whether the collagen impregnation contributes to the improvement of transplanted adipose tissue in rats and finally to contribute to establishing a more effective fat transplantation method.

\section{Results}

\section{Semiquantitative evaluation of the engraftment rate of the transplanted adipose tissue}

At one week and at 4 weeks after lipoinjection, the engraftment rate of the transplanted adipose tissue expressed by engrafted tissue length/transplanted tissue length was higher in the group with added collagen (control group vs. collagen group: 1 week ( $0.27 \pm 0.35$ vs. $0.52 \pm 0.37)$, 4 weeks $(0.27 \pm 0.41$ vs. $0.60 \pm 0.39$ ) (Table 1).

Table 1

Engraftment rate of the transplanted adipose tissue

\begin{tabular}{|lcc|}
\hline \multicolumn{1}{|c|}{ Control } & Collagen \\
\hline 1 week & $0.27 \pm 0.35$ & $0.52 \pm 0.37$ \\
\hline 4 weeks & $0.27 \pm 0.41$ & $0.60 \pm 0.39$ \\
\hline $\begin{array}{l}\text { At one week }(1 \mathrm{w}) \text { and at } 4 \text { weeks after lipoinjection, the engraftment rate of the transplanted adipose } \\
\text { tissue expressed by engrafted tissue length/transplanted tissue length. The result was expressed as } \\
\text { the engrafted rate } \pm \text { standard deviation. }\end{array}$ \\
\hline
\end{tabular}

\section{Histological evaluation}

As histological evaluations after adipose tissue transplantation, we performed HE staining and Perilipin staining. By evaluating the number of new blood vessels in the engrafted tissue on HE staining at 1 week and at 4 weeks, a greater number of new blood vessels was observed in the collagen group [control group vs. collagen group: 1 week ( $3.33 \pm 0.58$ /visual field vs. $14.33 \pm 0.58$ /visual field), and 4 weeks ( $3.33 \pm$ $1.15 /$ visual field vs. $23.33 \pm 4.93 /$ visual field)] $(n=3, p<0.05)$ (Fig. 1). Furthermore, on Perilipin staining of viable adipocytes, additional Perilipin-positive cells were reported in the collagen group (Fig. 2). These results suggested that in the group with collagen, greater angiogenesis and viable adipocytes were induced.

\section{Changes in cell count, and macrophage count caused by collagen impregnation}


Sliced control group and collagen group adipose tissue for transplantation were both injected into the back of an individual rat, and then engrafted tissue in the animal's back was extracted one week later $(\mathrm{n}=$ 12). In the extracted tissue, the total cell count, M1 macrophage count, and M2 macrophage count were analyzed using flow cytometry by fluorescence-activated cell sorting (FACS). Assuming the control group was 1.0, the collagen group had a significantly higher total cell count of $1.89(p<0.05), M 1$ macrophage count of $1.69(p<0.05)$, and M2 macrophage count of $2.19(p<0.05)$. These results suggest that collagen impregnation induces additional M1 and M2 macrophages (Fig. 3).

\section{Gene expression of adiponectin and VEGF in grafted adipose tissue}

To investigate whether collagen treatment improves the survival of transplanted adipose tissue, the expression of adiponectin mRNA, as a marker for functional adipocytes, was compared (Fig. 4a). At 1 week after transplantation, there was no significant difference between control- and collagen-treated grafts. The expression of adiponectin mRNA was similar at 1 week and 4 weeks after transplantation in control conditions. However, collagen treatment significantly increased adiponectin mRNA at 4 weeks compared to that at 1 weeks after transplantation $(p<0.05)$. To evaluate the effects of collagen on angiogenesis in grafts, the expression levels of VEGF mRNA were investigated (Fig. 4b). There was no significant difference between control and collagen-treated grafts, although the expression levels of VEGF mRNA seemed to be increased by collagen treatment at 4 weeks after transplantation. These results suggested that collagen treatment improve the functional adipocytes in the grafts at 4 weeks after transplantation, possibly via angiogenesis.

\section{Discussion}

Fat transplantation is extensively used as a postoperative reconstruction method such as craniofacial surgery and mastectomy; however, most of the transplanted adipose tissue is necrotic, engraftment is unstable, and developing more stable fat transplantation method is awaited. The engraftment instability of adipose tissue transplantation arises when the adipose tissue for transplantation is placed in an ischemic environment, and the transplanted adipose tissue developed necrosis $[2,7-9,12,13]$. To improve adipose tissue engraftment, we believe that it is important to reduce the cell count with necrosis arising from such ischemic environment, i.e., neovascularization and cell proliferation within the transplanted adipose tissue is required [13-15]. This study's results suggest that in rat adipose tissue, collagen impregnation to transplanted adipose tissue increases angiogenesis and improves the fat engraftment rate via the number of adipocytes and the proliferation of macrophages. In this study, adipose tissue transplanted into rats histologically promoted angiogenesis following collagen impregnation, thereby improving the engraftment rate. The tissue remodeling mechanism appeared to be involved in the increase in engraftment rate. After transplantation, the adipose tissue is placed in an ischemic environment, which causes tissue necrosis and tissue remodeling [16]. Macrophage migration is strongly involved in the process of such remodeling $[17,18]$. Macrophages are broadly divided into M1 and M2 macrophages. M1 macrophages induce the inflammatory reaction required for tissue 
engraftment, and they are involved in the scavenging of necrotic adipose tissue, whereas M2 macrophages are involved in tissue repair, and both $\mathrm{M} 1$ and $\mathrm{M} 2$ macrophages carry out an important role in the process of adipose tissue remodeling, and engraftment [18-23]. Furthermore, macrophages improve the survival of adipose tissue grafts by inducing neovascularization and activated stem cells [18, 24]. In this study, we reported that collagen impregnation to adipose tissue transplants significantly increased M1, and M2 macrophages in the transplanted tissue. In particular, M2 macrophages considerably increased, and we believe that this result reflects a state whereby impregnating transplanted adipose tissue with collagen induces the inflammatory reaction required for tissue remodeling and induces a potent tissue repair action $[19,24,25]$.

In this study, no significant difference was observed in the expression level of vascular endothelial growth factor (VEGF) mRNA, which is a factor that promotes neovascularization at 1 week and 4 weeks after transplantation; moreover, the level tended to be higher in the collagen group. This result might reflect the fact that impregnating transplanted adipose tissue with collagen serves as a platform for neovascularization and helps give rise to abundant neovascularization in the transplanted tissue. It is possible that the ligation and clustering of integrin receptors a1 $\beta 1 / \alpha 2 \beta 1$ on the surface of endothelial cells (EC) via the GFPGER (502-507) sequence of the collagen fibers is important for neovascularization activity [26]. While there is still room for debate, to summarize the results of the histological evaluation, we can draw the conclusion that collagen impregnation to transplanted adipose tissue produced additional neovascularization [25-27]. Recently, attention has been drawn to the effectiveness of adipose-derived stem cells (ASC) as a means to promote neovascularization in transplanted adipose tissue. ASC induce differentiation to adipocytes by co-culturing with mature adipocytes [28], and they contribute to neovascularization by differentiating into vascular EC [14, 29-32]. Furthermore, it has been reported that hypoxia results in the ASC secretion of neovascularization growth factors such as VEGF, and therefore induces neovascularization in an ischemic environment after transplantation [33]. ASC presents in subcutaneous adipose tissue can differentiate into adipocytes [34]; it has been reported that when ASC are cultured from collagen, more lipids are produced, which is a marker of adipose differentiation [35]. Therefore, collagen impregnation could support ASC differentiation into adipocytes. In this study, on comparing the level of adiponectin mRNA expression at 1 week and 4 weeks after transplantation; the expression level tended to be higher, although not significantly higher, in the control group. In the collagen group, a significant increase in the level of adiponectin mRNA expression was observed at 4 weeks. Furthermore, while there was no significant difference observed, at 4 weeks, the level of adiponectin mRNA expression tended to be higher in the collagen group than in the control group. Adiponectin is an adipocytokine produced particularly in adipose tissue and that produces and secretes various bioactive factors [36]. In humans, it is the gene with the most abundant expression in adipose tissue [37]. This study's results show that when collagen was added, there was a greater viable adipocyte count at 4 weeks after transplantation, which supports the higher engraftment rate in the collagen group indicated by semi-quantitative evaluation. Moreover, in the collagen group, there was a greater change over time from 1 to 4 weeks after transplantation. This suggests that collagen impregnation leads to greater viable adipocyte proliferation. Our results suggested that collagen impregnation increases the 
adipocyte count and increases neovascularization in the transplanted adipose tissue. It is possible that a greater effect can be anticipated by combining ASC with collagen, and therefore this needs to be studied further in future.

\section{Methods}

\section{Animals}

Approval was obtained from the animal care and use committee of Tokyo Medical University (Approval Number - H31-0056) for the protocol of all animal experiments, and all experiments were conducted in accordance with relevant guidelines. The study was carried out in compliance with the ARRIVE guidelines (https://arriveguidelines.org/arrive-guidelines). Female Sprague Dawley (SD) rats (Clea Japan, Inc.) aged 15-20 weeks were used. The rats were maintained in a breeding facility at a room temperature of $23^{\circ} \mathrm{C}$, with 24-h air conditioning, and a cycle of 12-h light and 12-h dark. Stainless steel cages that enabled individual feeding were used because each animal was maintained in a separate cage after injection.

\section{Harvesting adipose tissue and modification of adipose specimens for transplantation}

The rats were anesthetized by isoflurane inhalation with an intra-abdominal injection of a combination of three anesthetic agents, including medetomidine at $0.75 \mathrm{mg} / \mathrm{kg}$, midazolam at $4.0 \mathrm{mg} / \mathrm{kg}$, and butorphanol at $5.0 \mathrm{mg} / \mathrm{kg}$. Note that adipose tissue harvested from the inguinal region of the rats was thinly sliced using surgical scissors; after washing with physiological saline, centrifugal separation was performed $\left(1,800 \mathrm{rpm}\right.$ for $3 \mathrm{~min}$ at $\left.12^{\circ} \mathrm{C}\right)$. As the adipose specimen for transplant, we harvested the portion after removing the oil component in the supernatant and the fluid in the underlay, which was defined as the control group (Fig. 5). Bovine collagen suspension adjusted to a collagen concentration of $0.25 \%$ (Olympus Terumo Biomaterials) was added to the harvested adipose specimen for transplantation and used as the collagen group.

\section{Tissue transplant}

The adipose specimen for transplantation was then injected beneath the fibrous membrane on the back of the same individual rat, in addition to an adipose specimen for transplantation containing collagen using an $18 \mathrm{G}$ cannula to infuse $0.1 \mathrm{cc} / 1 \mathrm{~cm}$ (Fig. 6).

The adipose specimen for transplantation was injected to beneath the fibrous membrane on the back of the same individual rat, in addition to an adipose specimen for transplantation containing collagen using an $18 \mathrm{G}$ cannula to infuse $0.1 \mathrm{cc} / 1 \mathrm{~cm}$.

\section{Immunohistochemistry}

Perilipin (GP29, PROGEN, Heidelberg) was adopted for immunohistochemical analyses. Heat-induced epitope retrieval with antigen retrieval solution ( $\mathrm{pH} 9$, Nichirei Biosciences, Tokyo) was performed. 
Endogenous peroxidase activity was blocked by incubating in $0.3 \%$ hydrogen peroxidase and $0.1 \%$ sodium azide containing $0.01 \mathrm{M}$ phosphate-buffered saline, and a Histofine ${ }^{\circledR}$ simple staining system (Nichirei Biosciences) was used for secondary detection. The final product was visualized using 3,3凶diaminobenzidine.

\section{Isolation of mononuclear cells infiltrating to implanted fat tissue}

Implanted fat tissue was removed, washed with cold PBS, sliced with scissors into small pieces, and digested in PBS containing $1 \mathrm{mg} / \mathrm{ml}$ collagenase (Sigma-Aldrich) with gentle shaking at $37^{\circ} \mathrm{C}$ for $30 \mathrm{~min}$. After filtering through a $100-\mu \mathrm{m}$-sized nylon cell strainer, the single cells were collected and centrifuged, and then erythrocytes were lysed in the ammonium-chloride-potassium lysing buffer. After centrifugation, the cells were collected for flow cytometry analysis.

\section{Flow cytometry}

Cells were washed and incubated for 20 min at $4{ }^{\circ} \mathrm{C}$ with staining buffer (2\% FCS in PBS containing $0.02 \% \mathrm{NaN}_{3}$ ). Subsequently, the cells were stained with FITC-conjugated anti-CD163 (ED2, Bio-Rad), PEconjugated anti-CD86 (24F, BioLegend) and pacific blue-conjugated anti-CD45 (OX-1, BioLegend) or PEconjugated anti-CD3 (1F4, BioLegend) and pacific blue-conjugated anti-CD45. Then, the cells were fixed and permeabilized with a fixation/permeabilization solution kit (BD Biosciences) for $1 \mathrm{~h}$ at $4{ }^{\circ} \mathrm{C}$ in the dark, stained intracellularly with Alexa Fluor 647-conjugated anti-CD68 (ED1, Bio-Rad), and analyzed on a FACSCanto II Flow Cytometer (BD Biosciences), followed by analysis with FlowJo (Tree Star, Inc.; OR, US).

\section{Quantitative real-time PCR}

Total RNA of fat grafts was extracted as previously described [38]. High-capacity RNA to cDNA kit (Applied Biosystems, Life Technologies) was used for reverse transcriptase reactions. The expression levels of adiponectin and VEGF were determined using quantitative real-time PCR using ABI 7500 RealTime PCR system (Life Technologies). The expression level of the house-keeping gene GAPDH was used as an internal control. Primers and probes used for target genes were TaqMan Gene Expression Assays (Rn01775763_g1 for GAPDH; Rn00595250_m1 for adiponectin; Rn01511602_m1 for VEGF) purchased from Applied Biosystems, Life Technologies.

\section{Statistics}

Differences between multiple groups were analyzed using the Mann-Whitney U test. Statistical significance was set as p < 0.05 and analyzed using StatMate V (ATMS Co., Ltd., Tokyo, Japan).

\section{Conclusions}

On impregnating transplanted adipose tissue with collagen, we report that the level of adiponectin mRNA increased, and the histological viable adipocyte count increased in the rats. Furthermore, the level of VEGF mRNA tended to increase, and histologically an increase in neovascularization was observed, 
which suggested that collagen impregnation might contribute to increased neovascularization in transplanted adipose tissue in the rats. Moreover, we reported that collagen impregnation increased M1 and M2 macrophages in transplanted adipose tissue in the rats, and therefore might contribute to tissue remodeling. It was suggested that impregnating transplanted adipose tissue with collagen increases the engraftment rate of transplanted adipose tissue by increasing the viable adipocyte count, promoting neovascularization, and inducing macrophages.

\section{Declarations}

Acknowledgments: None

Author Contributions: C.S. designed the research, conducted experiments, and wrote the manuscript. H.I. contributed to perform the quantitative real-time PCR. T.Y. contributed to perform flow cytometry. T.K. have made substantial contribution to study design, interpretation of data, and made critical comments on the study. H.M. organized this research as project managers. All authors reviewed the manuscript.

Conflict of Interest: There are no conflicts of interest to declare.

Funding: This study received funding from Japan Society for the Promotion of Science grant number $16 \mathrm{~K} 11381$.

Data availability: The datasets generated during and/or analyzed during the current study are available from the corresponding author on reasonable request.

Ethics declarations: Approval was obtained from the animal care and use committee of Tokyo Medical University (Approval Number - H31-0056) for the protocol of all animal experiments, and all experiments were conducted in accordance with relevant guidelines.

Consent to participate/Consent to publish: Not Applicable

\section{References}

1. Billings, E. Jr. \& May, J. W. Jr. Historical review and present status of free fat graft autotransplantation in plastic and reconstructive surgery. Plast. Reconstr. Surg. 83, 368-381 https://doi.org/10.1097/00006534-198902000-00033 (1989).

2. Converse, J. M. Reconstructive plastic surgery, Vol. 1. 105-116(W B Saunders, 1964).

3. Konofaos, P. \& Arnaud, E. Early fat grafting for augmentation of orbitozygomatic region in Treacher Collins syndrome. J. Craniofac. Surg. 26, 1258-1260 https://doi.org/10.1097/scs.0000000000001722 (2015).

4. Delay, E., Garson, S., Tousson, G. \& Sinna, R. Fat injection to the breast: technique, results, and indications based on 880 procedures over 10 years. Aesthet. Surg. J. 29, 360-376 https://doi.org/10.1016/j.asj.2009.08.010 (2009). 
5. Illouz, Y. G. \& Sterodimas, A. Autologous fat transplantation to the breast: a personal technique with 25 years of experience. Aesthetic Plast. Surg. 33, 706-715 https://doi.org/10.1007/s00266-0099377-1 (2009).

6. Sinclair, N., Gharb, B. B., Papay, F. \& Rampazzo, A. Soft tissue reconstruction in patients with hemifacial microsomia: A systematic review of the literature. J. Craniofac. Surg. 30, 879-887 https://doi.org/10.1097/scs.0000000000005320 (2019).

7. Gause, T. M. et al. Particle size in fat graft retention: A review on the impact of harvesting technique in lipofilling surgical outcomes. Adipocyte. 3, 273-279 https://doi.org/10.4161/21623945.2014.957987 (2014).

8. Strong, A. L., Cederna, P. S., Rubin, J. P., Coleman, S. R. \& Levi, B. The current state of fat grafting: A review of harvesting, processing, and injection techniques. Plast. Reconstr. Surg. 136, 897-912 https://doi.org/10.1097/prs.0000000000001590 (2015).

9. Krastev, T. K., Alshaikh, G. A. H., Hommes, J., Piatkowski, A. \& van der Hulst, R. Efficacy of autologous fat transfer for the correction of contour deformities in the breast: A systematic review and metaanalysis. J. Plasti. Reconstr. Aesthet. Surg. 71, 1392-1409 https://doi.org/10.1016/j.bjps.2018.05.021 (2018).

10. Kirkham, J. C. et al. The impact of liposuction cannula size on adipocyte viability. Ann. Plast. Surg. 69, 479-481 https://doi.org/10.1097/SAP.0b013e31824a459f (2012).

11. Matsumura, H., Yoshizawa, N., Tanaka, I. \& Watanabe, K. Lipid fraction from subcutaneous fat improves angiogenesis and neodermis formation in the dermal substitute layer of bilayer artificial skin in a rat model. J. Burn Care Res. 22, S58-S58 https://doi.org/10.1097/00004630-20010300200027 (2001).

12. Pu, L. L. Mechanisms of fat graft survival. Ann. Plast. Surg. 77, S84-86 https://doi.org/10.1097/sap.0000000000000730 (2016).

13. Kato, H. et al. Degeneration, regeneration, and cicatrization after fat grafting: dynamic total tissue remodeling during the first 3 months. Plast. Reconstr. Surg. 133, 303-313 https://doi.org/10.1097/prs.0000000000000066 (2014).

14. Mou, S. et al. Extracellular vesicles from human adipose-derived stem cells for the improvement of angiogenesis and fat-grafting application. Plast. Reconstr. Surg. 144, 869-880 https://doi.org/10.1097/prs.0000000000006046 (2019).

15. Nürnberger, S. et al. Adipose-tissue-derived therapeutic cells in their natural environment as an autologous cell therapy strategy: the microtissue-stromal vascular fraction. Eur. Cells Mater. 37, 113$133 \mathrm{https}: / /$ doi.org/10.22203/eCM.v037a08 (2019).

16. Yuan, Y., Zhang, S., Gao, J. \& Lu, F. Spatial structural integrity is important for adipose regeneration after transplantation. Arch. Dermatol. Res. 307, 693-704 https://doi.org/10.1007/s00403-015-1574y (2015).

17. Kato, H. et al. Normobaric hyperoxygenation enhances initial survival, regeneration, and final retention in fat grafting. Plast. Reconstr. Surg. 134, 951-959 
https://doi.org/10.1097/prs.0000000000000600 (2014).

18. Phipps, K. D. et al. Alternatively activated M2 macrophages improve autologous fat graft survival in a mouse model through induction of angiogenesis. Plast. Reconstr. Surg. 135, 140-149 https://doi.org/10.1097/prs.0000000000000793 (2015).

19. Lee, W. J. et al. M2 macrophage polarization mediates anti-inflammatory effects of endothelial nitric oxide signaling. Diabetes. 64, 2836-2846 https://doi.org/10.2337/db14-1668 (2015).

20. Vogel, D. Y. et al. Human macrophage polarization in vitro: maturation and activation methods compared. Immunobiology. 219, 695-703 https://doi.org/10.1016/j.imbio.2014.05.002 (2014).

21. Novak, M. L. \& Koh, T. J. Macrophage phenotypes during tissue repair. J. Leukoc. Biol. 93, 875-881 https://doi.org/10.1189/jlb.1012512 (2013).

22. Liu, Y. C., Zou, X. B., Chai, Y. F. \& Yao, Y. M. Macrophage polarization in inflammatory diseases. Int. J. Biol. Sci. 10, 520-529 https://doi.org/10.7150/ijbs.8879 (2014).

23. Pollard, J. W. Trophic macrophages in development and disease. Nat. Rev. Immunol. 9, 259-270 https://doi.org/10.1038/nri2528 (2009).

24. Cai, J., Feng, J., Liu, K., Zhou, S. \& Lu, F. Early macrophage infiltration improves fat graft survival by inducing angiogenesis and hematopoietic stem cell recruitment. Plast. Reconstr. Surg. 141, 376-386 https://doi.org/10.1097/prs.0000000000004028 (2018).

25. Kang, P. L., Huang, H. H., Chen, T., Ju, K. C. \& Kuo, S. M. Angiogenesis-promoting effect of LIPUS on hADSCs and HUVECs cultured on collagen/hyaluronan scaffolds. Mater. Sci. Eng. C. 102, 22-33 https://doi.org/10.1016/j.msec.2019.04.045 (2019).

26. Twardowski, T., Fertala, A., Orgel, J. P. \& San Antonio, J. D. Type I collagen and collagen mimetics as angiogenesis promoting superpolymers. Curr. Pharm. Des. 13, 3608-3621 https://doi.org/10.2174/138161207782794176 (2007).

27. Karagergou, E. et al. Adipose-derived stromal vascular fraction aids epithelialisation and angiogenesis in an animal model. J. Wound Care. 27, 637-644 https://doi.org/10.12968/jowc.2018.27.10.637 (2018).

28. Considine, R. V. et al. Paracrine stimulation of preadipocyte-enriched cell cultures by mature adipocytes. Am. J. Physiol. 270, E895-899 https://doi.org/10.1152/ajpendo.1996.270.5.E895 (1996).

29. Matsumoto, D. et al. Cell-assisted lipotransfer: supportive use of human adipose-derived cells for soft tissue augmentation with lipoinjection. Tissue Eng. 12, 3375-3382 https://doi.org/10.1089/ten.2006.12.3375 (2006).

30. Planat-Benard, V. et al. Plasticity of human adipose lineage cells toward endothelial cells: physiological and therapeutic perspectives. Circulation. 109, 656-663 https://doi.org/10.1161/01.Cir.0000114522.38265.61 (2004).

31. Miranville, A. et al. Improvement of postnatal neovascularization by human adipose tissue-derived stem cells. Circulation. 110, 349-355 https://doi.org/10.1161/01.Cir.0000135466.16823.D0 (2004). 
32. Cao, Y. et al. Human adipose tissue-derived stem cells differentiate into endothelial cells in vitro and improve postnatal neovascularization in vivo. Biochem. Biophys. Res. Commun. 332, 370-379 https://doi.org/10.1016/j.bbrc.2005.04.135 (2005).

33. Rehman, J. et al. Secretion of angiogenic and antiapoptotic factors by human adipose stromal cells. Circulation. 109, 1292-1298 https://doi.org/10.1161/01.Cir.0000121425.42966.F1 (2004).

34. Zhang, J. et al. Allogeneic adipose-derived stem cells protect fat grafts at the early stage and improve long-term retention in immunocompetent rats. Aesthetic Plast. Surg. 39, 625-634 https://doi.org/10.1007/s00266-015-0505-9 (2015).

35. Zöller, N. et al. Collagen I promotes adipocytogenesis in adipose-derived stem cells in vitro. Cells. 8, https://doi.org/10.3390/cells8040302 (2019).

36. Maeda, K. et al. Analysis of an expression profile of genes in the human adipose tissue. Gene. 190, 227-235 https://doi.org/10.1016/s0378-1119(96)00730-5 (1997).

37. Maeda, K. et al. cDNA cloning and expression of a novel adipose specific collagen-like factor, apM1 (AdiPose Most abundant Gene transcript 1). Biochem. Biophys. Res. Commun. 221, 286-289 https://doi.org/10.1006/bbrc.1996.0587 (1996).

38. Guan, H. \& Yang, K. RNA isolation and real-time quantitative RT-PCR. Methods Mol. Biol. 456, 259270 https://doi.org/10.1007/978-1-59745-245-8_19 (2008).

\section{Figures}


a

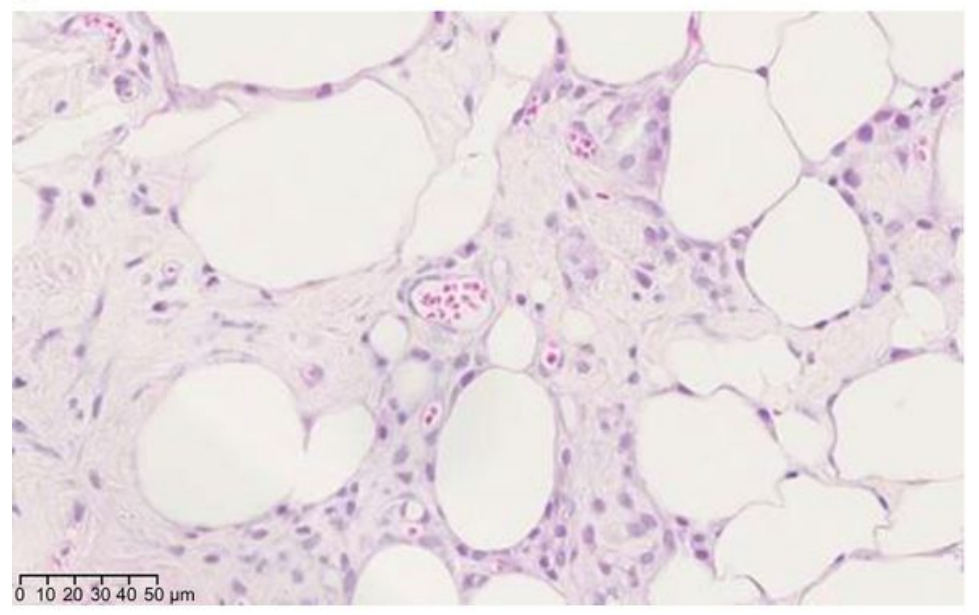

C

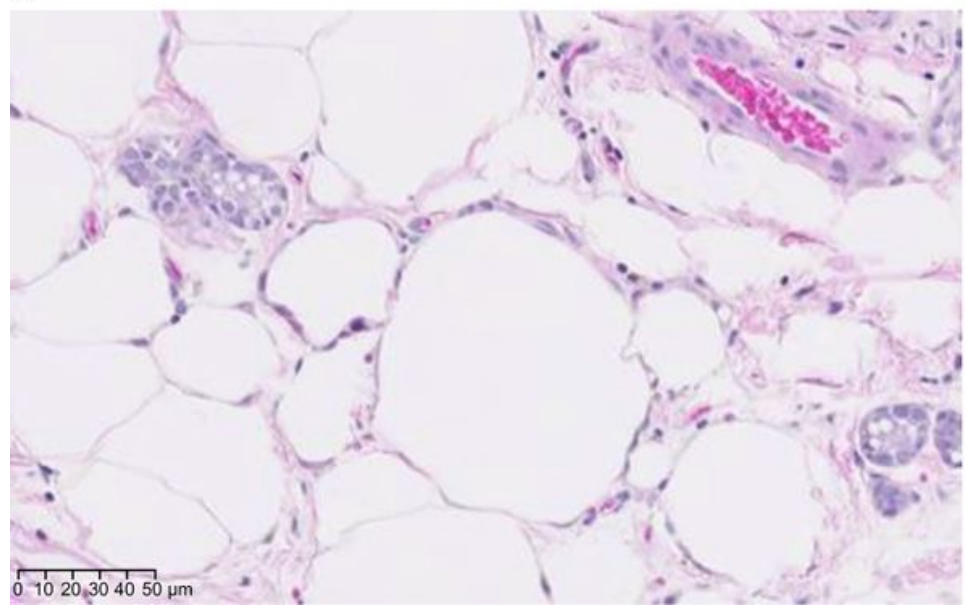

b

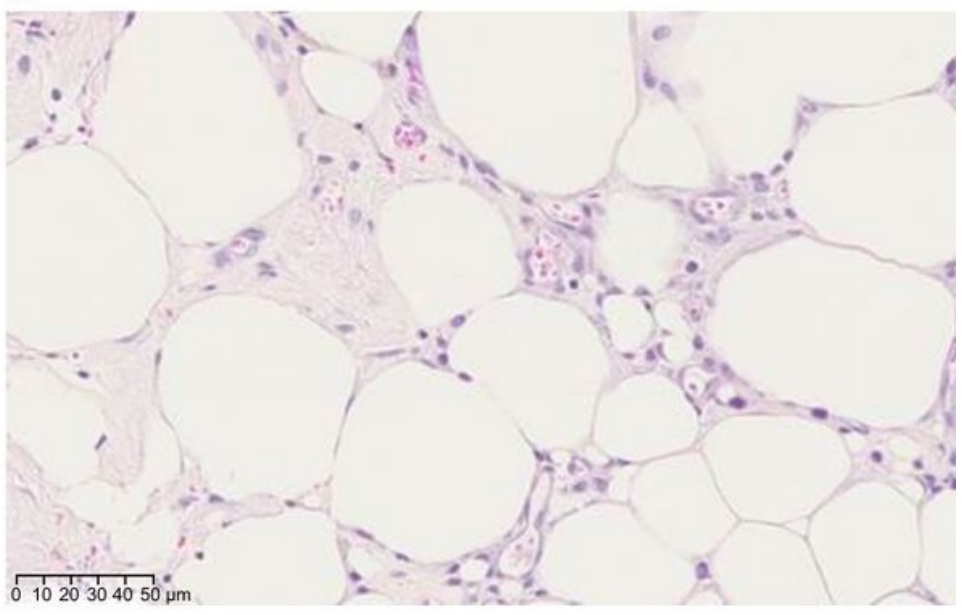

d

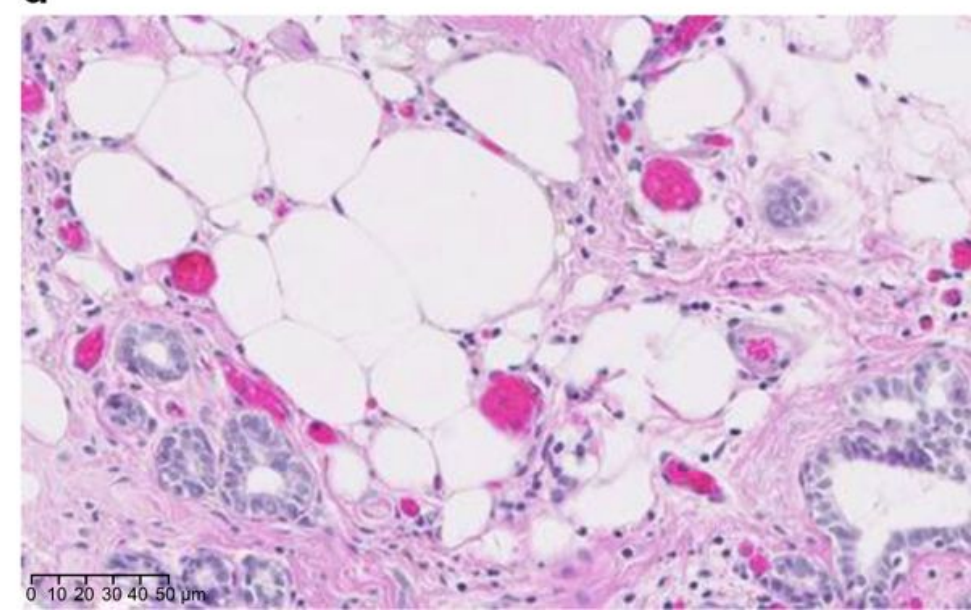

\section{Figure 1}

Histological evaluations of the engraftment tissue. HE staining was performed for (a) the control group at 1 week, (b) the collagen group at 1 week, (c) the control group at 4 weeks, and (d) the collagen group at 4 weeks. The number of new blood vessels in the engrafted tissue was then evaluated.

a

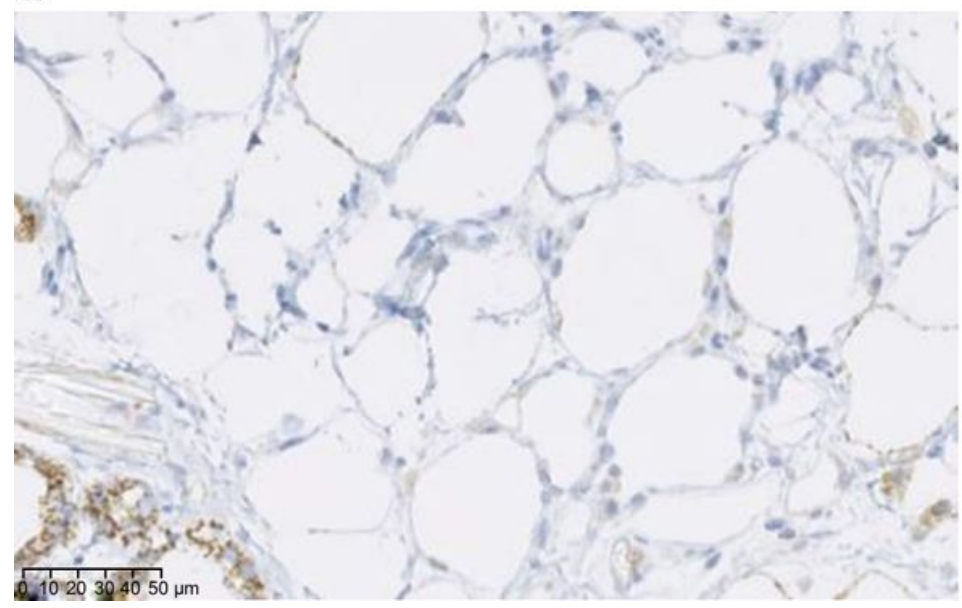

b

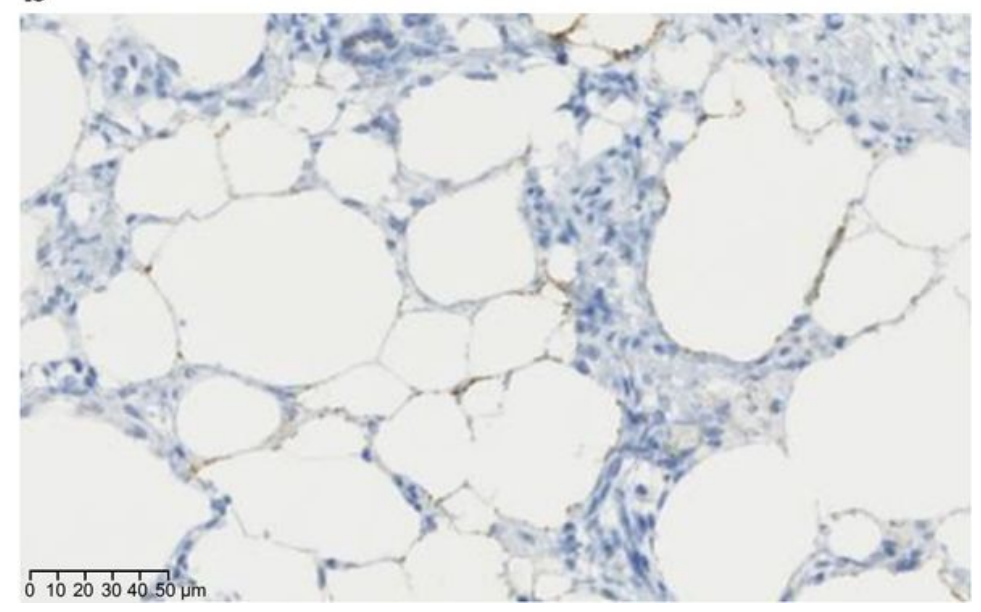

Figure 2 
Immunohistochemistry of the engraftment tissue. Perilipin staining was performed for (a) control group and (b) collagen group. Perilipin-positive cells were then counted as viable adipocytes.

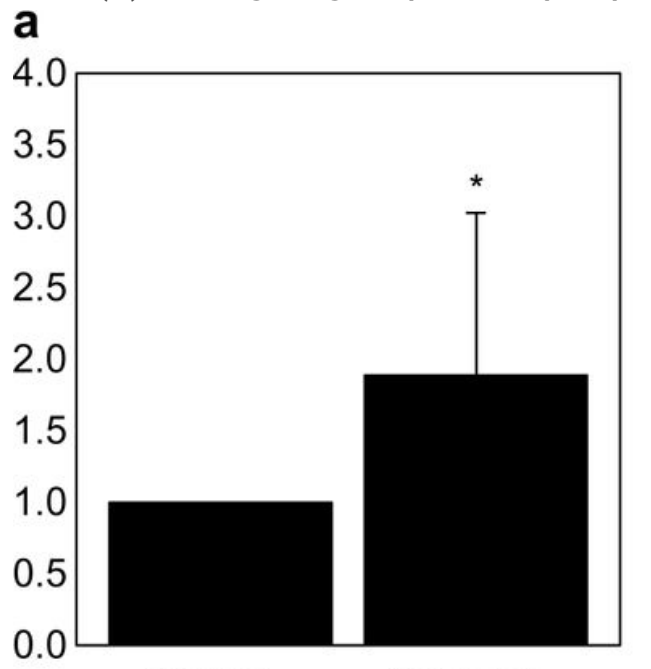

Control b

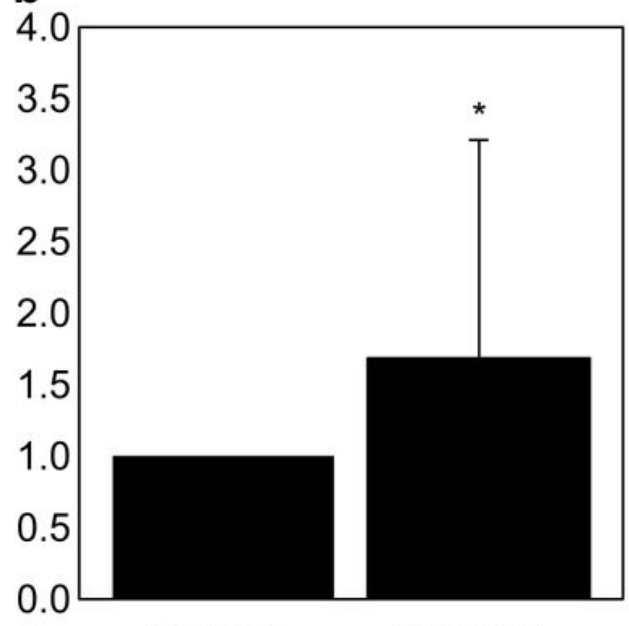

Control Collagen
C

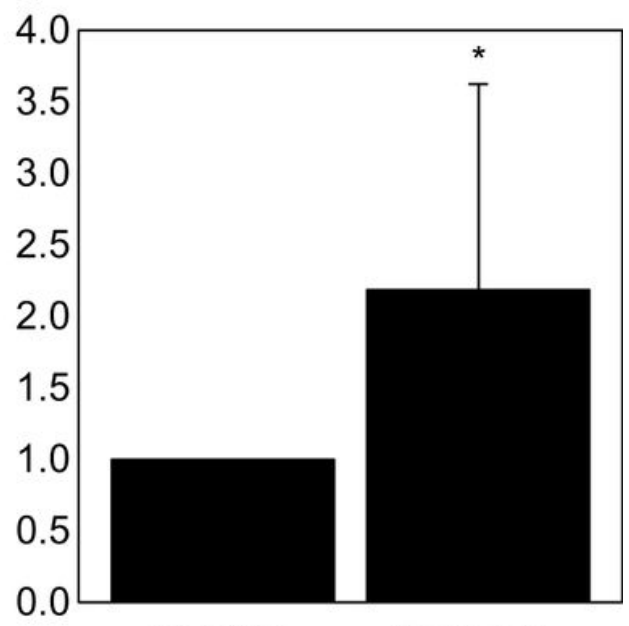

Control

Collagen

Figure 3

Cell Proliferation and macrophage activity in the engraftment tissue. Engrafted tissues of control group and collagen group were evaluated (a) total cell number, (b) M1 macrophage number, and (c) M2 macrophage number by flow cytometry $(n=12, * p<0.05)$.

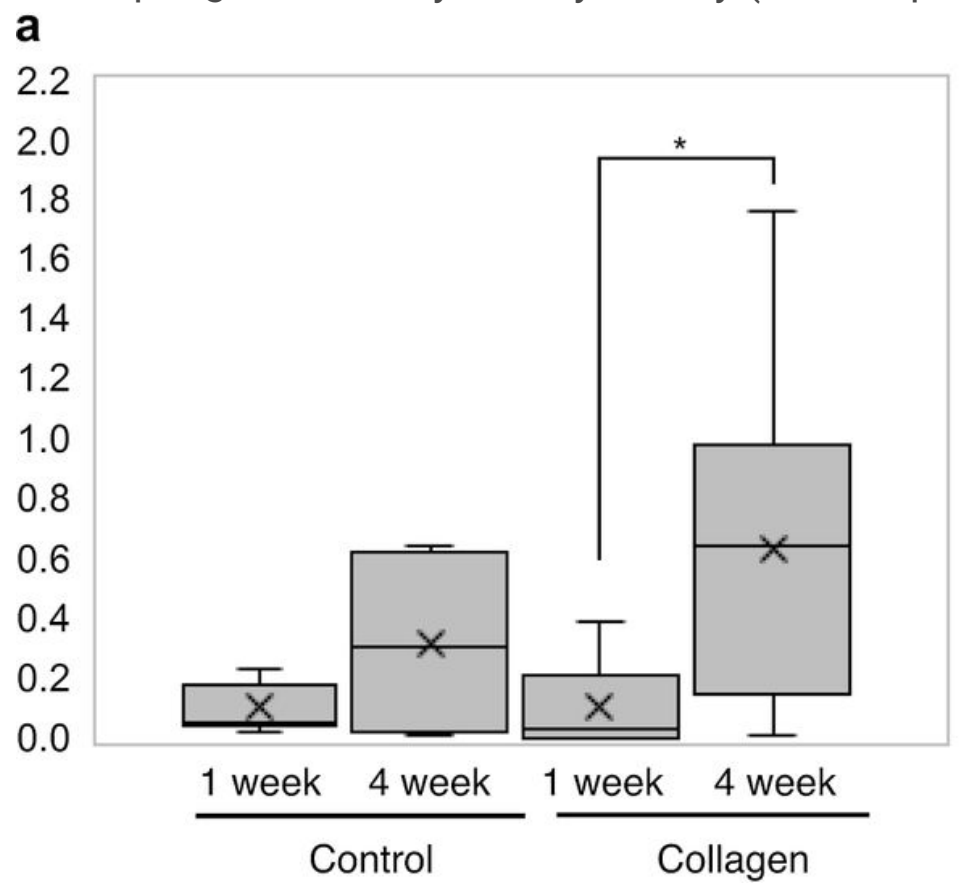

b

0.050
0.045
0.040
0.035
0.030
0.025
0.020
0.015
0.010
0.005
0.000

Figure 4

Gene expression in the engraftment tissue. Engrafted tissues of control group and collagen group were evaluated Adiponectin mRNA and VEGF mRNA expression by quantitative real-time PCR. (a) Adiponectin [Control Group 1-week: $0.11 \pm 0.087(n=7)$, 4-week: $0.32 \pm 0.30(n=5)$, Collagen Group 1-week: $0.10 \pm 0.14$ 
$(n=8)$, 4-week: $0.63 \pm 0.55(n=10)$ ], (b) VEGF [Control Group 1-week: $0.0081 \pm 0.0059(n=7), 4$-week: 0.014 $\pm 0.0073(n=5)$, Collagen Group 1-week: $0.015 \pm 0.012(n=8), 4$-week: $0.030 \pm 0.023(n=10)]\left({ }^{\star} p<0.05\right)$
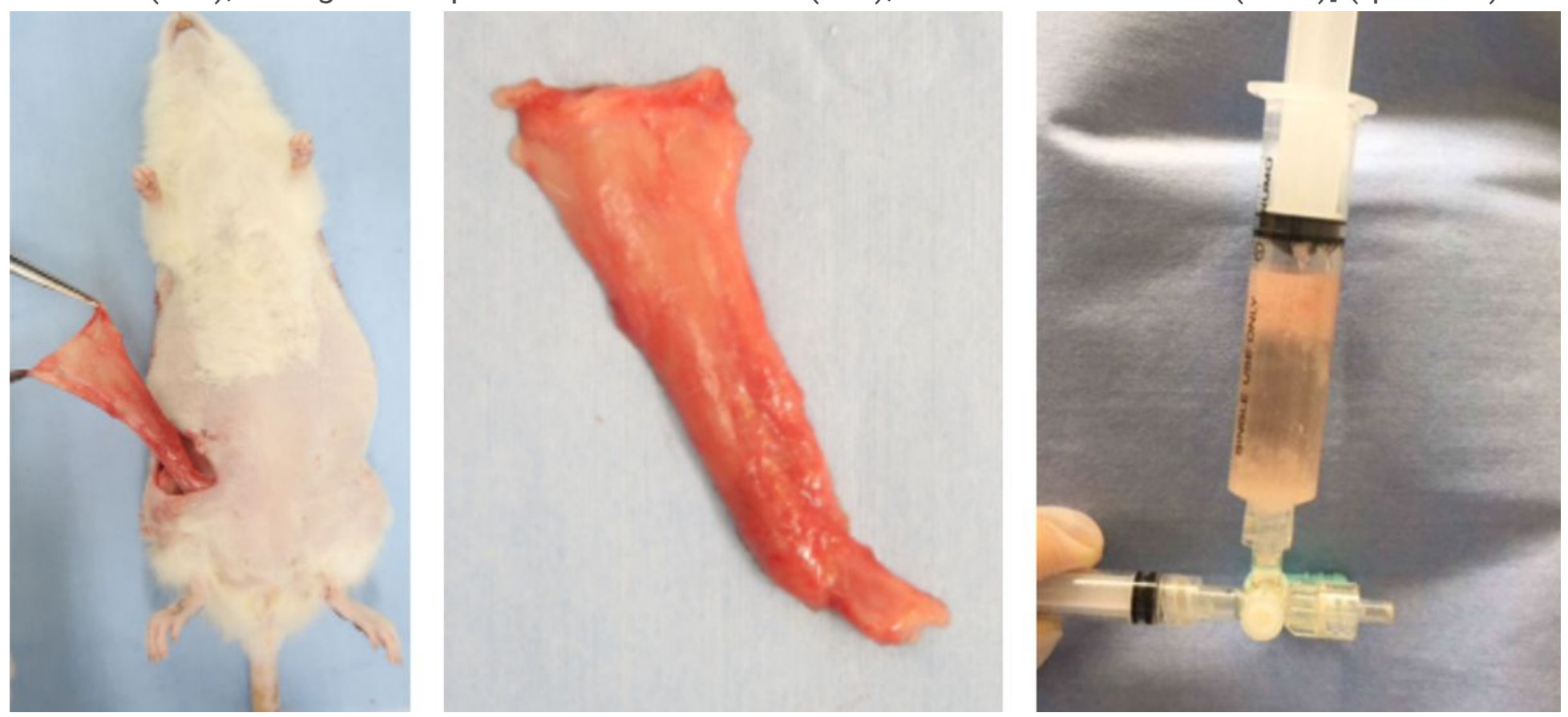

\section{Figure 5}

Adipose tissue for transplantation. Adipose tissue is harvested from the inguinal region. Harvested adipose tissue was thinly sliced using surgical scissors; after washing with physiological saline, centrifugal separation was performed $\left(1,800 \mathrm{rpm}\right.$ for $3 \mathrm{~min}$ at $\left.12^{\circ} \mathrm{C}\right)$. As the adipose specimen for transplant, we harvested the portion after removing the oil component in the supernatant and the fluid in the underlay.
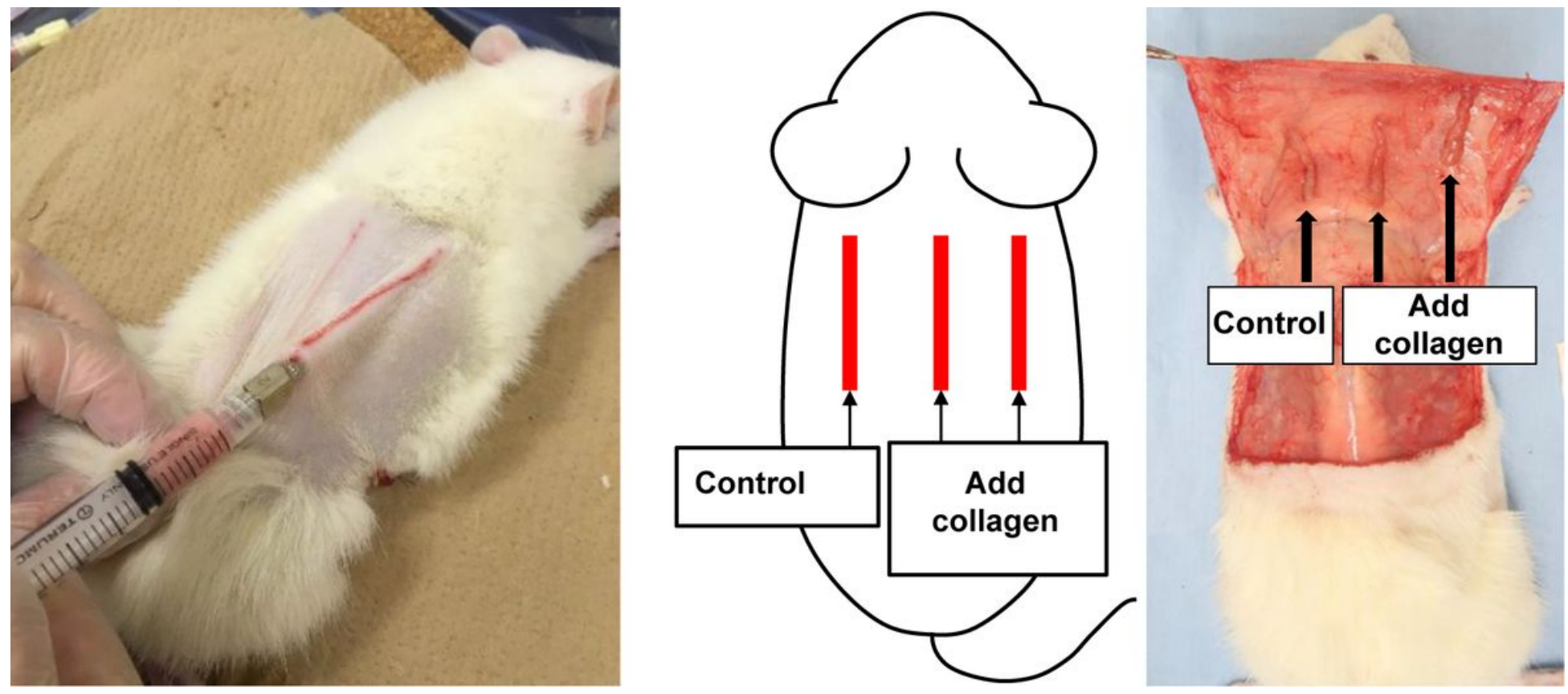

Figure 6 
Transplantation of the adipose specimen. The adipose specimen for transplantation was injected to beneath the fibrous membrane on the back of the same individual rat, in addition to an adipose specimen for transplantation containing collagen using an $18 \mathrm{G}$ cannula to infuse $0.1 \mathrm{cc} / 1 \mathrm{~cm}$. 